\title{
WORKING-CLASS VISIBILITY IN RACHEL SEIFFERT'S THE WALK HOME
}

\author{
Andrew Monnickendam
}

Universitat Autònoma de Barcelona

\begin{abstract}
Lawrence Driscoll argues that contemporary fiction and current criticism are no longer concerned with social class in general and the working class in particular. Identity now uses more flexible parameters, such as sexual orientation, a term that defines the individual as agent. He analyses a wide range of literary fiction and film in order to highlight that 'class' often means middle class. When authors do focus on the working class, it is usually in a negative fashion, infused by bourgeois prejudice.

The second half of this article strives to see to what extent the Driscoll hypothesis is valid through applying his findings to Seiffert's very recent novel. It refutes the argument that postmodern techniques necessarily produce apolitical texts, and puts into question other assumptions.
\end{abstract}

Keywords: Rachel Seiffert, The Walk Home, Lawrence Driscoll, Evading Class in Contemporary British Literature, identity, fiction.

\section{Resumen}

Driscoll propone que la novela y discurso crítico contemporáneos dan poca importancia a las clases sociales en general y la clase obrera en especial. Hoy día, La identidad humana se construye con parámetros más flexibles, como, por ejemplo, la orientación sexual, un término que define la persona como agente. Driscoll analiza una amplia gama de ficción literaria y películas con el fin de subrayar que la palabra 'clase' a menudo se asocia con "la clase media." Cuando los autores dirigen su interés hacia la clase trabajadora, normalmente la retratan de una manera negativa,

La segunda mitad del artículo intenta averiguar hasta qué punto la hipótesis de Driscoll es válida, mediante la estrategia de aplicar sus conclusiones a la recién publicada novela de Seiffert. El artículo arrebata la teoría que la escritura posmoderna necesariamente produce textos apolíticos, y cuestiona otros presupuestos cercanos.

Palabras clave: Rachel Seiffert, Lawrence Driscoll, la novela contemporánea, identidad, clase social. 


\section{Is there a class in this text?}

Driscoll's Evading Class in Contemporary British Literature (2009) has a self-explanatory title. His analysis, which extends into film, is informed by and acknowledges the work of two prominent Marxist critics, Terry Eagleton and Fredric Jameson. All three scholars are highly critical of postmodernism for having jettisoned history, a situation epitomised by the impact of Francis Fukuyama's The End of History and the Last Man (1992) which, they believe, misrepresents the contemporary world. Driscoll attacks on two fronts. His sights are set on the humanities as a whole, in fact, on all those disciplines where society is visible. The adjective is chosen with care, as he proposes there are not simply "clear evasions" but also "erasures of class" (Driscoll 1). If Driscoll's views are tenable, they will undoubtedly reflect on the teaching praxis of many readers of this article, as he stresses that erasure is embedded in current academic discourse. His second object of analysis comprises a cross-section of contemporary fiction which, in similar terms, shows little sympathy for the working-class. Its centre of attention, its authors and their viewpoints are, for Driscoll, unremittingly bourgeois, in the most negative sense possible of the word.

Virginia Woolf's remark that the human character changed around December 1910 is an oft-cited adage that conflates history and literary history: the approaching catastrophe of total war with modernism. Similarly, the Fukuyama premise of a major ideological swing in the 1980s is paralleled by a corresponding shift in British literary history: the demise of the old guard, rapidly replaced by a bevy of new, energetic writers ready to incorporate postmodernity-as-freedom into their texts, Salman Rushdie's Booker Prize for Midnight's Children (1981) being the watershed event. This celebration of hybridity paints a striking contrast with the more traditional prose of the four previous winners: William Golding, Penelope Fitzgerald, Iris Murdoch and Paul Scott. Midnight's Children, from this perspective, induced a sea-change. For Driscoll, the downside of this radical transformation has been that literature and criticism are now "overwhelmingly focused on identity politics" (Driscoll 2), on race, gender and sexual orientation. He does not rate cultural studies highly either. Despite its early Marxist orientation it has moved on, though he would argue that the discipline has moved backward, because of its heavy reliance on reading "the world through the rather limited lenses of the postmodern" (Driscoll 3). Why the postmodern produces a blinkered vision might initially seem peculiar, as hybridity would initially offer countless opportunities, or, at least, much more than the work of Golding and his contemporaries. Driscoll's reasons will soon become clear.

His monograph builds on several key concepts most notably articulated several years earlier in Eagleton's The Illusions of Postmodernism (1996). Due to the text's all-pervading sense of irony, he can be a difficult critic to judge.

Social class tends to crop up in postmodern theory as one item in the triptych of class, race and gender, a formula which has rapidly assumed 
for the left the kind of authority which the Holy Trinity occasionally exerts for the right. The logic of this triple linkage is surely obvious: racism is a bad thing, and so is sexism, and so therefore is something called "classism". "Classism", on this analogy, would seem to be the sin of stereotyping people in terms of social class, which taken literally would mean that it was politically incorrect to describe Donald Trump as a capitalist. (Eagleton 56-7)

Leaving aside the debatable veracity of the analogy -it is nonsensical not to call Donald Trump a capitalist- Eagleton is himself indulging in that kind of textual game he often dismisses, nonetheless two points are clear. Relativism has installed itself as the left's bogey man. Second, just as race and gender, as strict categories, are restrictive, by some historical accident the roots of which are not identified other than as postmodern in a general sense, class has become part of a demonic troika. Class allegiance as the primary identity marker or, more precisely, working-class allegiance, has become something to be frowned on, a relic of the old order, whether this be a historical reflection (pre-Fukuyama), or a literary one (pre-Rushdie). Driscoll extends this finding to underpin his disquiet with contemporary understanding of both history and culture.

He acknowledges that modern pedagogy has opened up our understanding of society by focussing on the margins and marginalized, but laments that this has been at the cost of obscuring "the working-class subject...in the hope of producing a supposedly 'classless' norm" (Driscoll 3). At the risk of redundancy, the norm is classless because it refutes class as the overriding allegiance, instead, promoting the citizen as agent. For a critic of the left (and perhaps others), since the working-class make up the bulk of the population, this looks rather spurious, as the 1980s witnessed not only a rise in poverty but an ever widening gap between rich and poor. As Driscoll states, "Britain has become more divided by class and inequality, not less" (Driscoll 8). John Hutchinson, in Reaganism, Thatcherism and the Social Novel (2008), delves farther. Erasure not only occurred in the world of culture, but, most exasperatingly, in politics. The Labour Party in the 1980s and 1990s sidelined social class: "Instead, they relied upon avowedly instinctive and pragmatic appeals to morality and fairness that seemed to have more in common with religious nonconformism than with dialectal materialism" (Hutchinson 55-6).

This is simply a further illuminating example of how far the classless norm had penetrated political life. The election of Jeremy Corbyn as Labour Party leader in 2015 illustrates a very different ideological stance that aims to redress this change of policy, or, within the language of this debate, to put an end to the erasure of the working-class.

Eagleton and Driscoll believe that an essential epistemological flaw lies at the centre of contemporary identity politics: it ignores or is ignorant of history. Eagleton, for example, goes to some length to point out Marx's sometimes favourable opinion of the bourgeoisie in order to confound expectations that he only expressed hostility (Eagleton 61). However, for Eagleton, the bourgeoisie is 
"on the whole a bad thing today" (Eagleton 57). It is therefore essential to historicize, not only when discussing the Labour Party or Marx. The antipostmoderns take exception to the pronouncements of Jean-François Lyotard on the death of grand narratives; unsurprisingly, history, the grandest of narratives, became the major victim. Eagleton sarcastically affirms that "[p]erhaps postmodernists are afraid that an attention to grand narratives will collapse all little narratives into mere effects of them" (Eagleton 57). It is worth recalling that the relationship between the individual and history lies at the centre of much of the writing of the greatest Marxist critic of all, György Lukács, who, when analysing Scott and the historical novel states that "Scott endeavours to portray the struggles and antagonisms of history by means of characters who, in their psychology and destiny, always represent social trends and historical forces" (Lukács 33).

If history is amputated from literary criticism, we are left with ahistorical characters and texts, a scenario in which literature no longer has a social function. Instead, it will revert to solipsism. Driscoll proposes that that is exactly what has occurred to contemporary fiction.

The implication for the present day runs along lines like this. Paradoxically the modern subject lives in a historical moment that lacks all sense of history. Eagleton ironizes on postmodern objections to universalism (Eagleton 49); Driscoll emphasises the classlessness of identity politics. Both critics propose that it is absurd to assert that that people can be " "free' from history" (Driscoll 4). They seem to imply that history is repeating itself: postmodernism almost returns to the allegedly ideal Leavisite world, where works of art float in an eternal, universal space.

Driscoll analyses a considerable cross-section of contemporary literary fiction: Pat Barker, Ian McEwan, Kazuo Ishiguro, Zadie Smith, Will Self, Martin Amis, Peter Ackroyd, Alan Hollinghurst, Jonathan Coe, Hanif Kureishi, among others. All of these authors write in the Fukuyama world, one marked by globalisation, otherwise known as late capitalism, or, in Driscoll's laconically coined term, the "supposedly 'new' economic environment" (Driscoll 135). To illustrate his approach, I have chosen Hollinghurst and Martin Amis as representative examples.

Hollinghurst is certainly a figure at the centre of the literary world: what could be a better illustration of establishmentarianism than the job of deputy editor of the Times Literary Supplement? His first three novels, and in particular the 2004 Booker Prize winner, The Line of Beauty, served to make gay literature academically respectable, and forward the cause of gay rights. Driscoll approaches the novel through the lens of the critic Kaye Mitchell. For those unfamiliar with the text, suffice it to say that Driscoll rests his findings on the way we read the fate of two gay men. The first is Leo, who is black and workingclass. Driscoll asks rhetorically how a critic like Mitchell, and by extension the academy as a whole, circumvents class issues (Driscoll 138). A short answer would be, based also on the work of Eve Sedgwick, that gay sex is disruptive, 
exposes boundaries, queers the status quo, threatens hegemony, without confronting social class. Living gay sexuality is an emancipating act for individuals, yet remains, in Driscoll's scheme of things, ultimately a classless norm.

Driscoll, aware of the predictable criticism that the working class is definitely not Hollinghurst's major concern, cites an interview in which the novelist states that he has little knowledge of working-class life (Driscoll 142). This therefore leads us to a conundrum. Leo contracts AIDS, he "dies 'off stage': the novel avoids confronting his illness directly, and he only returns to the novel once he is dead...In contrast, the illness of the upper-class Wani spans all of part three of the novel" (Driscoll 142). In short, erasure of one character contrasts strongly with the developing tragedy of another. As can be appreciated here, Driscoll combines interpretation with quantitative analysis, as the absence of one gay man is underscored by the extensive depiction of another. Driscoll argues the imbalance is the logical consequence of class prejudice. The novel shows "that not only are the three classes of British society clearly mapped out, but that they are also shown to be unable to mix, blend or unravel in any substantial way "(Driscoll 143). Identity politics liberates the individual, legitimises certain practises, but draws very clearly defined borders between those whose identity we are witnessing and those we are not.

Martin Amis's Money (1984) is certainly one of, if not the most controversial of the 1980 s texts. The novel recounts the life story of a character called John Self, who draws checks on his account without realising the consequences. No one could really contest the proposition that the novel subsequently draws a huge parable on consumption. Driscoll's analysis of this picaresque novel, in which Self rises and falls, seems to indicate that the lesson to be learnt is that absolute consumerism consumes absolutely. However, Driscoll refines his analysis, pointing out that John Self -despite the universal tendencies inherent in his name- is not the everyman of the Thatcher-Reagan era, but a working-class citizen. Hence, "the real target of Amis's satire is his working-class characters" (Driscoll 102). In other words, “Amis's satire functions through re-establishing and reinforcing a class system that is felt to be under threat from below" (Driscoll 108). In a gloss on Winston Smith's belief expressed in 1984- that there was some hope in the proles, according to this critic, in the new economic order, that remote eventuality has been deleted from the political panorama.

Driscoll's most incisive strategy is, arguably, his analysis of domestic space. It is there that Driscoll's selected authors reveal deep-seated class prejudice. Of many examples he analyses, I will mention just a couple: Hollinghurst's description of a council house; Zadie Smith's description of the two houses in On Beauty (2005). In both cases, the lower the economic status, the more uncomfortable the major characters feel. To use an obvious pun, they do not feel at home in a poor person's home. In film, the situation is no different. In his analysis of Mike Leigh's Abigail's Party (1977), Driscoll asserts that the joke about Beverly putting a bottle of Beaujolais in the fridge turns out to be, in 
the end, a joke about gaucheness. Leigh, it is worth recalling, is frequently praised precisely for something rather different: his meticulous accounts of working-class life that otherwise find no place in commercial cinema. ${ }^{1}$ Although one might argue that there is a fine line between laughing with or at someone's behaviour, Driscoll would say that lately mainstream culture favours the latter.

Driscoll's most telling example of spatial politics derives from the Harry Potter saga.

The household [Harry's] is entirely claustrophobic and it is also narrative-phobic insofar as the film's real story cannot get underway while the camera (and Harry) remains in the house. The working-class environment cannot be a magical space, and Harry must escape from it. (Driscoll 185)

Again, as is the case with Hollinghurst, the "narrative-phobic" provides vital evidence. Driscoll develops such an argument for two good reasons. First, he is anticipating the reproach that his field of vision is restricted to literary fiction, and therefore of limited significance. Hence, he pinpoints class intolerance as a cornerstone of one of the most successful media enterprises of recent times. Second, he is presumably aware that the slippage from identifying a character's opinion to linking it to the overall ideology of a text is open to criticism from all shades of opinion.

Harry Potter takes the train to freedom: but to what kind of freedom? Does it have anything to do with a classless norm? On the contrary, what Harry escapes to is a fantasy version of that most elitist institution of all, the Public School, particularly in its boarding version. The working-class home, as metonym for class, is what aspiring children must leave in order to fulfil their often artistic- destiny. Evading Class in Contemporary English Literature therefore shares many of the findings of Owen Jones's Chavs: The Demonization of the Working Class (2011), especially as regards the origins of this demonization and additionally its omnipresence in mainstream culture from the 1980s to the noughties. This brings us to the final point of the first section of this article, which is one which Driscoll could perhaps have insisted upon more emphatically.

All the texts mentioned show awareness of working-class life, though often, as mentioned, this is restricted to origins and/or confinement. Driscoll's insistence on academic collusion in the erasure of class difference might strike readers of critical volumes on contemporary literature as somewhat odd if not completely mistaken. For example, Philip Tew's influential The Contemporary British Novel (2004) begins in a similar way to Driscoll, with references to Thatcherism, reiterates Britain's rigid class structure (Tew 8), avowing that "in Britain class is an elusive or protean concept" (Tew 65). Tew therefore recognises, uncontroversially, that class maintains its hold in Britain. Yet, for

\footnotetext{
${ }^{1}$ Driscoll admires Ken Loach. Whereas Leigh veers towards the condescending, he judges Loach's films to be genuine.
} 
Driscoll, that is just part of the story, as can be seen in this remark on Tew's volume: "Once the 'class' chapter is over, he returns to talking about the contemporary novel as it were once again politically and ideologically transparent" (Driscoll 22). Tew, and, by extension, most of the academy, restrict the question of class to its middle class parameters. In a similar fashion, Dominic Head has a very short section on "The Waning of Class-Consciousness", dedicating a lot more time and space to the identity markers that Driscoll critiques.

Driscoll and his opponents hold fundamentally different views about the representation of the working-class in the 1980s and beyond. To say that class is protean, or to gently discard its significance and regard it as -metaphorically- a chapter on its own rather than as a major influence, results not simply in evasion, as Driscoll argues, but in a fundamental disagreement over identity. As we saw earlier, his quarrel with identity politics is twofold: it sidesteps history; it provides the citizen with agency that Driscoll and others believe might exist in a postmodern set-up but not in the real (material) world.

This discrepancy is evident in Tew's remark about the protean nature of class. Similarly, Hutchinson argues that "[b]oth Money and [Alan Warner's] Morvern Callar [1995] are instances of contemporary British novels that indicate both erosion of the self and the decline of class-based political antagonism, as both are dissolved in a culture of media-driven consumption" (Hutchinson 170). The metaphorical use of dissolving or protean underscores the central epistemological debate: is class, like other identity markers, malleable, or is it simply disappearing in our contemporary world? Clearly, in the industrialized world, the poor are ever more numerous than before, but poverty does not constitute a working class or the accompanying consciousness that Marxist criticism continually emphasises. Perhaps Slavoj Zizek's thoughts cast light on the subject when he says that "working class designates a pre-existing social group, characterized by its substantial content while people emerges as a unified agent through the very act of nomination" (Zizek 574). We can therefore determine that traditional working-class allegiances have been seriously eroded, even leading to certain nostalgia about the past (Eagleton 55). Perhaps, in the teens, critics are as saddened by the loss of traditional Gesellschaft as nineteenthcentury authors were of Gemeinschaft. If that, and nothing else mattered, then the Driscoll hypothesis would collapse, having no foundation in either history or literature. However, Driscoll, knowingly or unknowingly, does not overtly distinguish between the working class of industrial societies and the poor of the post-industrial era. That may or may not represent an unpardonable error of judgement, but in contemporary literature it makes slight or no difference at all, as fiction also avoid confronting the repercussions of this difference. If Driscoll is right, the hostility shown to the traditional working class prior to Fukuyama is now simply directed to the poor en masse irrespective of their pertaining to older blue-collar sectors or newer service industries or families who depend entirely on benefits. Within Driscoll's parameters, old hostility has ceded to new hostility. As he points out, Will Self's How the Dead Live (2000) spookily reveals that 
class antipathy is so deeply engrained in British culture that it is still alive and flourishing in the afterlife.

\section{Is class evaded in this text?}

In the second part of this article, I will analyse Rachel Seiffert's The Walk Home (2014) through the theoretical framework provided by Driscoll. I have chosen this novel because it provides a good match through its focus on working-class life. It is structured on identity politics, as understood by Driscoll and Eagleton, though it integrates something which they omit: religious affiliation. As its recent publication-date might suggest, it incorporates another factor of growing importance in the new world order: economic migration. I stated earlier that Driscoll is keenly aware of the importance of space, particularly antipathy towards working-class housing, something which acts throughout this particular novel as a motif if not almost a character in its own right. I will try to assess how Seiffert's novel addresses Driscoll's concerns and whether it provides answers or alternatives.

I will now provide a brief summary of The Walk Home that readers familiar with the text are invited to skip. From multiple viewpoints, through standard chronology and numerous flashbacks, the text narrates a Glaswegian family history through four generations, focussing mostly on Stevie, the youngest character, whose life and opinions have been formed by its turbulent past. The first generation, Papa Robert's family, were forced to leave Louth (Leinster) during the Irish Civil War and settle in Glasgow. The second generation comprises his son Eric and his daughter Brenda, who marries Malcolm. The couple have three children. The youngest, the adolescent Graham, buys a drum and gets involved in marching bands, without sharing the more extreme views of his Orange grandfather. During a trip to Ulster, he meets Lindsey. On getting pregnant, she moves to Glasgow where their only child Stevie is born. The novel narrates how all those elements that make up identity disturb and break up the family. The main victim is Stevie, who drops out of school and disappears. The Walk Home of the title initially refers to his return to Glasgow in the latter part of the novel. He comes back to help complete the building of a house, working for a group of Poles. Novel summaries usually sound confusing, so it might be helpful to say that the novel explores how a loner, who lives on the outskirts of society, comes into being.

Seiffert's choice of Glasgow as a location responds in part to her years of residence there. Of greater significance is the fact that Scottish urban fiction is the one glaring exception to Driscoll's ruling that contemporary literature evades class. ${ }^{2}$ Using a more traditional style, we find the work of William McIlvanney.

\footnotetext{
${ }^{2}$ My term "Scottish urban fiction" hopefully ensures that the focus is on urban communities in Scotland. As Drew Milne states throughout his chapter on Welsh and Kelman, both writers include highly critical remarks on Scottish nationalism and Scottish politicians in their fiction. They are primarily concerned with the fate of the poor and the underprivileged.
} 
Two exponents of a grittier, more oral urban prose are James Kelman and Irvine Welsh. Driscoll's title refers to British rather than English literature, so the scarce visibility of these important practitioners of class awareness is surprising, to say the least. In contrast, Tew, who Driscoll lambasted for his scanty attention to class matters, certainly deals with Kelman and Welsh, and in addition, Alison Kennedy. Although he spends most of a rather limited time on Kelman, Tew proposes that all three novelists "typify a more mundane and sceptical approach to the urban" (Tew 111). Driscoll would counter and ask us to inquire into what exactly Tew means by "urban": prosperous Bearsden or the poverty-stricken Gorbals? Hampstead or Tower Hamlets?

Reflecting on Kelman's The Busconductor Hines (1984), oddly enough misspelt, Tew argues that

The dialect of the narrator that is close to Rab's [Hines] own speech emphasizes a male perspective of working-class marginality, detailing a world of drinking, boring work, marital worries and relative poverty...Nevertheless, the influence of modernist narratives of fragmentation and chains of diverse causalities remain strong. The city is not simply actions, but encompasses conscious resistance to past and present...His very incoherence and confusion reveals [sic] the inability of the social narrative to reflect the dispossession of such lives as his own. (Tew 112)

First of all, the proposal that Rab is incoherent cannot be left unanswered. As Tew himself explains on the next page, he is keenly aware of modern economics. The comment about fragmentation makes greater sense with Kelman's later works, most notoriously in How Late it Was, How Late (1994), than with this earlier text. For similar reasons, the idea that the city encompasses "conscious resistance" is far too abstract a term for Kelman. His social narratives describe the miseries of dispossession in material terms: low pay, the threat of unemployment, and so on. Similarly, when dealing with Welsh's Trainspotting (1993), oddly enough moved from Edinburgh to Glasgow, Tew emphasises both the self-destructive life of drug addiction and the text's innovative language that attacks, challenges and subverts conventional English. So we are left in a situation, which Driscoll continually identifies as critical ambivalence, where we are not sure whether such texts are lauded for their treatment of the workingclass or for their postmodern style.

In this particular case, Driscoll might reply, the latter: Tew's abstraction of city life, turning it into nebulous sites or spaces avoids confronting the question of social reality other than as a subject for an exciting new literary medium. Furthermore, it is Driscoll who points to the well-known fact that Kelman has repeatedly rejected the standard third-person narrative. For him, it is permeated by many ideological assumptions: "[g]etting rid of that standard third party narrative voice is getting rid of a whole value system....is trying to get down to that level of pure objectivity" (McNeill 4, 5). Put another way, "pure objectivity", as an ideal or aspiration, will not be common in traditional 
narratives that make up Driscoll's corpus. If Kelman's belief is correct, it is not surprising that Driscoll's search for no-nonsense accounts of working-class life was unfruitful. He was looking in the wrong place.

From the above analysis, it must surely be evident that one of the major consequences of postmodern literary freedom, exemplified by the Derrideaninspired figure of the endless chain of signifiers, is that postmodernism has become equated by critics on the left with excessive literary virtuosity. Seiffert's strives for "that level of pure objectivity" through removing any excess narrative baggage that would conceivably be misconstrued. Nevertheless, this practise is not limited to, for example, standard asyndeton, the removal of conjunctions, but extends to considerable doses of intense ellipsis, reminiscent of Hemingway and the iceberg theory. An example of the former would be, "His red head was cut close, and the back of his skinny neck too pale, blue-pale above his T-shirt" (Seiffert 2). A testing example of the latter is: "Jozef looked at him, doubtful, on the doorstep; at his red hair and freckles, and the way he squinted in the summer light, the June sun already up above the rooftops" (Seiffert 1). It certainly requires some effort to appreciate that "the way he squinted" is possibly the third object of the verb "looked at", though perhaps it is not that at all but the beginning of a new idea. Likewise, in the space after the final comma, attention has turned to the sun, which almost becomes the subject of a new utterance. This particular narrative strategy is used extensively, as shown by another instance a few pages on: "It was a treat to come home to that: a first chink in the girl's armour plating, plus a good meal into the bargain" (Seiffert 23). Again, the final comma requires the reader to fill in a considerable gap. Likewise, the reader is not informed that these are Brenda's thoughts, we simply know or deduce from earlier references to specific characters. In addition, Seiffert, whenever possible, avoids direct identification of her characters' speech, unless it is necessary in order to avoid confusion. She also uses a considerable amount of postmodification, as illustrated here: "The girl gave a small smile, wry, when she saw Brenda" (Seiffert 23). To cite another example at random, we find, "The boy gave that same nod-shrug again, his eyes not on Jozef but the Glasgow morning, blue beyond the garden door "(Seiffert 3). Although changed word order can affect assonance, alliteration or sibilance, as in the last-but-one example, or lead to estrangement, as in the final example, "blue beyond the door", I believe there is a lot more at play than literary refinement. If Seiffert's dialogues are analysed, similar patterns, on a less complex level, emerge. Right at the beginning, Jozef laments the poor quality of the plasterwork, telling Stevie, "I know. I know. Not good enough. But the one who did these walls, he's gone now" (Seiffert 2). What is "[n]ot good enough" is the workmanship, but such a depth of implied meaning could tax the reader. In other words, it is certainly the case that Seiffert uses techniques that are identified as postmodern, or, when used so intensely are considered as such. Among these are the multiple viewpoints, the constant switching of time and place, the lack of authorial voice as authority, but her major contribution is, as these examples show, to consciously write narrative as speech, thus blurring the distinction between the two. In itself, this does not constitute innovation, but rarely is its use so persistent in its endeavour, in line 
with Kelman's pronouncement to erase all superfluity from the narrative. Is this simply free indirect discourse by another name? I believe not, as it would be safe to say that the narrative talks and thinks like any of the text's characters without aligning itself with anyone in particular. If free indirect discourse highlights convergence and conflation, Seiffert's style heightens diversity and divergence.

What is all this virtuosity for? From the Eagleton-Driscoll angle, the answer would run along the lines of 'not much', highlighting its detachment from reality and entry into abstract textuality. As we saw, for them, postmodernism is defined by its disconnection from history. In pinpointing Seiffert's sophisticated narrative techniques, I am suggesting that she hones language to its minimum expression, revealing a wish to present things as they are, as free from authorial intervention on the one hand, as from the presumed ideological baggage of the third person narrator, on the other. The Eagleton-Driscoll dichotomy, I would conclude, is a false one. Seiffert, along with Kelman, Welsh, and McIlvanney, focuses on the presence and role of violence in contemporary Scottish workingclass life, but her narrative does not follow the more traditional style of McIlvanney, uses a more approachable language than Kelman or Welsh, and is light on expletives. Her narrative is postmodern; her approach, social, but whereas Driscoll might join the two phrases together with the conjunction 'but', I would argue that is not the case: 'and' makes perfect sense.

How does gender interact with class politics in The Walk Home? Two women influence Stevie's character and behaviour: his mother, Lindsey, and his paternal grandmother, Brenda. That Stevie is essentially their child rather than being a product of male culture is evident on several occasions. Aged four, he "knew he was like his mother: they had the same hair, and the same bird bones, everybody said so" (Seiffert 33). What could be a throwaway, gratuitous set of childish impressions, turns out to be more profound than that, as we shall soon see. The only person he maintains contact with when he runs away from home is his grandmother; that is the essential bond.

Brenda is very much the centre of family life, both economically and socially. Not only does she keep up with Stevie during his absence, but also with the errant, eccentric Uncle Eric. In other words, all communication passes through her, so she becomes the natural mediator when, for example, Lindsey and Graham's marriage hits the rocks. She is also the only person who contacts Lindsey's family in County Tyrone. If we look at the situation from a different perspective, it would be fair to say that no narrated communication occurs without her presence or knowledge. Her company and advice are much sought after, but there is little or no exchange.

We have scanty knowledge of her experience of motherhood. The information we receive suffices to define it as a youthful, taxing experience. Maternal anxiety is understated but intense: she has "two sons in the army, and endured their Ulster tours of duty" (Seiffert 17). She is sandwiched between one generation that was forced to leave Ireland and another that returns to a place where both factions share a common belief: "No thought of surrender allowed 
there" (Seiffert 17). There is simply no let-up. Her son Malcolm drifts back to the bands and certainly looks towards a future as an Orangeman. Lindsey disappears, Malcolm more or less gives up on his son, so the person who has to deal with Stevie's truancy is his grandmother. Her life is determined primarily by economic factors, both those present in traditional working class life, as set out by Richard Hoggart in his classic The Uses of Literacy (1957), for example, and those belonging to the new economic order-Lindsey and Malcolm meet in the early 1990s (Seiffert 7). Brenda's low pay and full responsibility clearly reflect her gender, but it is a gendered situation in a specifically identified social stratum: it is a class-defined norm.

I praised Driscoll's analysis of spaces; Seiffert focuses on two separate levels. As I previously noted, the context within which her novel is inscribed is very much that of postwar Scotland, hence the affinity with Kelman and others. In addition, it is difficult to find a more iconic representation of that era than the Glasgow tenement building, both in its construction and demolition. This is the site and timeline of The Walk Home. Indeed, it might be considered complementary to Andrew O'Hagan's Our Fathers (1999), a fictional recreation of the utopian ideals and subsequent failure of the tenement project.

Brenda's family live in Drumchapel, an enormous housing estate built in the 1950s to ease Glasgow's chronic housing shortage. Like many such schemes, it suffered from poor infrastructure, infrequent public transport, and a lack of shops. It would be predictable enough to construct a novel that puts down Stevie's waywardness to a Drumchapel childhood, but Seiffert does not take that path. Occasionally, there are remarks which have an ironic tinge, for example: "You could see down as far as Glasgow"(Seiffert 49). Drumchapel is, of course, part of Glasgow, so the distance has presumably more to do with enforced isolation than geography.

On the contrary, the scheme ${ }^{3}$ provides its characters with a sense of identity. In the light of Eagleton's remarks on nostalgia and the fact that the novel is located "now or thereabouts" (Seiffert 1), we should be aware that that community described is inevitably a mixture of the real and the perceived. Certainly, all the family live there (Seiffert 36), but Lindsey is primary aware of practical issues:

Lindsey had given up on the buggy...because the new flat was on the highest part of Drumchapel, and there were flights of steps all over...They had to go down them to get anywhere, and then it was a steep haul to get up again... (Seiffert 36)

By the 1990s, it has become rundown; however, Brenda and

\footnotetext{
${ }^{3}$ BBC Scotland's television documentary The Scheme (2010-11) gives an idea of what these projects have become in our century. The Scheme should not be confused with Channel 5's Benefits Britain that concentrates more on how benefit money is spent, therefore promoting the belief that many beneficiaries are scroungers.
} 
...her family got moved out here when she was six. They'd come from the tenements in the middle of Glasgow, with hundreds of other folk besides, mums and dads and kids, and Stevie had heard all about those uprooted families making a new go of it; how the closes were smart then, the steps kept scrubbed, half the place was still empty and high flats not yet built. (Seiffert 37)

This description moves from the factual, the large scale uprooting, a period of low rise housing before the construction of tower blocks, to the mediated, when Brenda remembers those times as the good old days: "How the closes were smart then". Seiffert therefore seems conscious of the Eagleton argument about nostalgia, and provides a satisfactory answer to the overlap between reality and memory. It is true that Brenda's three sons all live in Drumchapel, but more important than location is the fact that they all have homes of their own. Brenda's emphatic remark to Lindsey when they move to a flat, "It's your ain place" (Seiffert 34), would similarly indicate that for her at least a home is of greater importance than the community. She prioritizes the familial over the social.

Lindsey and Graham's marriage breaks down precisely because he refuses to move to a better home. The narrative, in an ironic litotes, tells us that Whiteinch "wasn't a scheme, it was proper streets" (Seiffert 137). A housing scheme is metonymically depicted by its poor or inexistent streets and infrastructure. The apposition, the colloquial "was proper streets", also emphasises improvements. That is the material truth, but Graham refuses to move because, in his own words, "I dinnae know emdy that lives round there" (Seiffert 138). He prioritizes community; she, mod cons. However, the argument goes much deeper than this. I have mentioned Brenda's pivotal role as family peacekeeper. The novel insists that the sense of community, working-class community let us not forget, is strong, while at the same time heightening its dependence on gender to maintain itself. If Brenda was not there, the family would implode. Lindsey has no desire to fulfil this traditional female role, and takes the only way out, flight. Her son will later follow in her footsteps.

In the most lyrical section of the book, described in most detail in chapters twenty-two, when he is supposedly at school, and twenty-six, when he has returned to Glasgow, Stevie spends hours in deserted tower blocks. At the risk of repetition, the tenement block is an icon of postwar Glasgow and is there infused with symbolic meaning. The boarded-up buildings become his refuge. Entering them is a minor challenge, but climbing up to the heights represents the real test, especially when competing with two other like-minded boys. Some of the flats still contain personal objects, "sofas and cookers and broken kids' toys" (Seiffert 224). The scheme has become obsolete, "falling off down the hill beyond the gutter rim, all grey and brown, walls and roads, rust-red pipes and railings" (Seiffert 232); that much is clear. But the more difficult question to answer is why have things fallen apart? It is certain that the blocks were put up in a hurry and not built with the best of materials, as Hagan's novel sets out in great detail. It is also true that the corresponding undertaking of providing the working-class 
with a modern community has failed, too. So, using Seiffert's suggestive phrasing, what exactly has fallen down off the hill: the housing scheme itself or the working class as a social category? The first is materially visible, and second becomes more so when we integrate Seiffert's migration sub-plot.

Stevie's epiphany when looking down from the ruins of the modern Glasgow project is immediately followed by a description of one of the boys' adolescent games: changing the taps around in twelve newly-built houses in a modern cul-de-sac. What is juxtaposed, then, is the buildings of the past and those of the present, Stevie himself fulfilling the role of nexus. A few years later, on his return to Glasgow, he will work on building homes of the latter type. Not only, then, do we witness one form of living being replaced by another, but also the replacement of the Glasgow working-class by migrant workers, Poles in this case. What I think is outstanding here is that Seiffert's awareness is not constricted to workers as individuals, but extends to the organisation of labour. That is to say, what is most salient is that the person in charge of the building is himself a Pole, Jozef, who employs other Poles. Stevie has become an outsider in his own city. This then, represents a sample of the new economic order: different homes built by different workers that have no allegiance or connection to the history of the British working-class or its culture or consciousness. My earlier remarks on Seiffert's style should prepare us for the non-judgmental depiction of this reality. Stevie is unfairly dismissed, accused of stealing, even though Jozef tells Stevie that he knows he is innocent; the other Poles do not want him around. They have their sense of identity while Stevie apparently has none. Much to his chagrin, he will find out he retains one that is unfortunately indelible.

A few pages before the novel's end, Stevie runs into three men, one of whom wears a Celtic football shirt. Stevie falls to the ground, but rather than help him up, one cries out, "He's a dirty Orange cunt, Frankie. Leavum" (Seiffert 280). They remove his new trainers, throw them up into the air so they caught on the telephone wires, and force his head down on to the pavement, "mashing the side of his face against the tarmac". The chapter concludes with "Why the bloody hell did it have to be like this?" (Seiffert 281). From my previous remarks on Seiffert's prose, we should note that the final rhetorical question is not placed inside inverted commas, so although the thoughts are Stevie's, there are not exclusively Stevie's, and serve to influence the way identity operates in the novel.

The men have identified Stevie as Orange from a patch on his jeans, which has appeared at several junctures. Right at the beginning, we are told that the "boy had a patch on his knee, sewn on badly, with a hand pictured on it: a red one, held up, palm forward, No Surrender stitched underneath. Jozef hadn't been there long, but he suspected that was from a football club" (Seiffert 3). The hand in question is the red hand of Ulster. Although the origins of the symbol and its history do not conform to one version, it is most notorious for being displayed by loyalist paramilitaries, and above all, by the UDF (Ulster Defence Force), consequently it is most prominent during the summer marching season. The patch was sewn on by his father (Seiffert 238), much to Brenda's disgust. To 
recap, it is precisely Malcolm (Stevie's father) who gradually drifts back to playing the drum, replacing his family life with Protestant politics, sympathising with extreme Orange positions outside the law. This indicates why 'the walk' of the book's title refers not to Stevie's return alone but also to Protestant marching. Jozef's estranging remark about a football team highlights two facts. First, that sectarianism is still a potent force in Glasgow politics. Second, that is precisely in the Rangers-Celtic rivalry that this hatred is most raucous, leading to Rangers supporters' bigotry, as identified in their songs and chants, being commonly labelled "Scotland's shame". At the same time, Celtic supporters are well known for their singing of inflammatory IRA songs. Commentators differ as to how extensive this polarised intolerance is in Scottish society. ${ }^{5}$

Stevie painfully realises that the strongest component of Glasgow identity politics is the Orange divide. He is unable to shed this tie. How much of the hate and intolerance that poisoned Papa Robert's life still lives on across the water remains an open question, but essentially one of degree, as the truth is that it has a very long shelf life. The following generation try to be more tolerant, but the third, Malcolm, returns to the past, and the fourth, Stevie, is beaten up. The question of bigotry permeates the text from the beginning, but if there is a surprise in store for the reader, it must surely be that at the end of the day, it is the most powerful signifier of all, arguably more so nowadays as working-class consciousness has fallen off down the hill. Sectarianism, however, thrives whatever the economic and social climate.

To conclude, therefore, we have to return to Driscoll's hypothesis on evasion. Does Seiffert's text, as a representative example of modern fiction, evade class in its fixation on identity politics? I hope to have proved that is not the case. First, as I have previously stated, there is no evidence that evasion and postmodernism inevitably go hand in hand. Second, where that argument also falls down is in its lack of historicity. This might seem an odd thing to say about a Marxist-based critic of the Eagleton school, but nevertheless, that is the case. The absence of working-class consciousness and the prevalence of snobbery surely exist, but this cannot function as a definite sentence without considering, as Seiffert certainly does, how deeply social and economic models have undergone modification in the last twenty years ago, due to the end of older economic models and mass migration. The parameters of class have to be adjusted, otherwise critics will interpret the present with outmoded concepts. Seiffert's text would suggest that if that change is required for class, other identity markers have their own timeline and agenda. In the case of Glasgow, sectarianism has survived those alterations and still marches on to the sound of the drum.

\footnotetext{
${ }^{4}$ Tom Devine edited Scotland's Shame: Bigotry and Sectarianism in Modern Scotland (2000), which allowed both Catholics and Protestants to expose their views on the subject.

${ }^{5}$ In contrast to sectarianism at club level, followers of the national team, the tartan army, have a reputation for being peaceful and non-violent. The whys and wherefores are concisely set out by Hugh O’Donnell (2010).
} 


\section{WORKS CITED}

Driscoll, Lawrence. Evading Class in Contemporary British Literature. Basingstoke: Macmillan, 2009. https://doi.org/10.1057/9780230622487

Eagleton, Terry. The Illusions of Postmodernism. Oxford: Blackwell, 1996.

Head, Dominic. 20002. The Cambridge Introduction of Modern British Fiction, 1950-2000. Cambridge: Cambridge UP.

Hutchinson, Colin. Reaganism, Thatcherism and the Social Novel. Basingstoke: Macmillan, 2008. https://doi.org/10.1057/9780230594906

Lukács, Georg. The Historical Novel. Translated by Hannah and Stanley Mitchell. Harmondsworth: Penguin, 1981.

McNeil, Kirsty. "Interview with James Kelman." Chapman 57 (1989): 1-9.

Milne, Drew. "The Fiction of James Kelman and Irvine Welsh." Contemporary British Fiction. Eds. Richard J. Lane, Rod Mengham and Philip Tew. Cambridge: Polity, 2003. 158-173.

O'Donnell, Hugh. "Class Warriors or Generous Men in Skirts? The Tartan Army in the Scottish and Foreign Press." From Tartan to Tartanry, Scottish Culture, History and Myth. Ed. Ian Brown. Edinburgh: Edinburgh UP, 2010. 212-31.

https://doi.org/10.3366/edinburgh/9780748638772.003.0014

Seiffert, Rachel. The Walk Home. London: Virago, 2014.

Tew, Philip. The Contemporary British Novel. London: Continuum, 2004.

Zizek, Slavoj. "Against the Populist Temptation." Critical Inquiry 32.3 (2006): 551-74. https://doi.org/10.1086/505378

Received: 7 October 2016

Accepted: 16 November 2016 